\title{
Storms or cold fronts: what is really responsible for the extreme waves regime in the Colombian Caribbean coastal region?
}

\author{
L. J. Otero, J. C. Ortiz-Royero, J. K. Ruiz-Merchan, A. E. Higgins, and S. A. Henriquez \\ Applied Physics Group - Ocean and Atmosphere Area - Physics Department, Universidad del Norte, Barranquilla, Colombia \\ Correspondence to: L. J. Otero (ljotero@uninorte.edu.co)
}

Received: 9 April 2015 - Published in Nat. Hazards Earth Syst. Sci. Discuss.: 4 May 2015

Revised: 28 December 2015 - Accepted: 4 January 2016 - Published: 8 February 2016

\begin{abstract}
The aim of this study is to determine the contribution and importance of cold fronts and storms to extreme waves in different areas of the Colombian Caribbean in an attempt to determine the extent of the threat posed by the flood processes to which these coastal populations are exposed. Furthermore, the study wishes to establish the actions to which coastal engineering constructions should be subject. In the calculation of maritime constructions, the most important parameter is the height of the wave. For this reason, it is necessary to establish the design wave height to which a coastal engineering structure should be resistant. This wave height varies according to the return period considered. The significant height values for the areas focused on in the study were calculated in accordance with Gumbel's extreme value methodology. The methodology was evaluated using data from the reanalysis of the spectral National Oceanic and Atmospheric Administration (NOAA) WAVEWATCH III ${ }^{\circledR}$ (WW3) model for 15 points along the $1600 \mathrm{~km}$ of the Colombian Caribbean coastline (continental and insular) between the years 1979 and 2009. The results demonstrated that the extreme waves caused by tropical cyclones and those caused by cold fronts have different effects along the Colombian Caribbean coast. Storms and hurricanes are of greater importance in the Guajira Peninsula (Alta Guajira). In the central area (consisting of Baja Guajira, and the cities of Santa Marta, Barranquilla, and Cartagena), the strong impact of cold fronts on extreme waves is evident. However, in the southern region of the Colombian Caribbean coast (ranging from the Gulf of Morrosquillo to the Gulf of Urabá), the extreme values of wave heights are lower than in the previously mentioned regions, despite being dominated mainly by the passage of cold fronts. Extreme waves in the San Andrés and Providencia insular region present a different dynamic from
\end{abstract}

that in the continental area due to their geographic location. The wave heights in the extreme regime are similar in magnitude to those found in Alta Guajira, but the extreme waves associated with the passage of cold fronts in this region have lower return periods than those associated with the hurricane season.

\section{Introduction}

The principal source of coastal energy and cause of sediment dynamics are waves. The waves generated by "sea"-type local winds and those generated offshore by atmospheric disturbances (swells) determine the average and extreme maritime climate of a region. The activities which develop in coastal or maritime areas, such as fishing, transport, oil exploitation, structure design, and even recreational activities (surfing etc.), require knowledge of waves. The maritime climate (wind in particular) is a dynamic phenomenon which presents short-period (daily, weekly etc.), seasonal, and longterm variations. Considering the fact that wind is the main agent of wave generation, wave variation is also based on this pattern. Given the impact of the wave climate on the operation and construction costs of maritime infrastructure, it is imperative to design such structures with knowledge of the temporal variation of this phenomenon at an oceanic and local scale in mind.

Cold fronts occur when two air masses at different temperatures and densities come into proximity. The cold air mass with higher density pushes the hot air, making it ascend. The rising hot air cools down, producing clouds, storms, strong winds, and the pressure gradient in the area. Furthermore, it 
increases the wave height or swell through its passage along the Colombian Caribbean coast (Ortiz et al., 2013).

The incidence of cold fronts in the Colombian Caribbean coast has not been widely studied. Cold fronts are noted in the marine meteorological monthly reports of the Center of Oceanographic and Hydrographic Research (Centro de Investigaciones Oceanográficas e Hidrográficas, $\mathrm{CIOH}$ ) of the General Maritime Direction (Dirección General Marítima, DIMAR). Their potential impact on the instances of extreme waves in the region was described by Ortiz et al. (2014), where the most important marine meteorological event of the last 10 years in the Colombian Caribbean was reconstructed. This event was the passage of a cold front in March 2009, when the associated waves caused $200 \mathrm{~m}$ of the pier at Puerto Colombia to collapse.

Ortiz et al. (2013) presented a characterization of cold fronts in the central region of the Colombian Caribbean and their relationship with extreme waves. The findings concluded that cold fronts have been the cause of the major waves in this region over the last 15 years.

Ortiz (2012) and Ortiz et al. (2015) also described the threat of hurricanes in the Colombian Caribbean. Hurricane Joan in 1988 and Hurricane Lenny in 1999 were two of the most important events which affected the continental Caribbean coast. San Andrés and the insular region have, for their part, been consistently impacted over the past 50 years (Hurricane Hattie in 1961, Hurricane Alma in 1970, Hurricane Joan in 1988, Hurricane Cesar in 1996, Hurricane Katrina in 1999, and Hurricane Beta in 2005). This demonstrates that the San Andrés y Providencia Archipelago is the zone in the Colombian Caribbean which is most vulnerable to hurricane threats.

Within this context, the traditional method of constructing the extreme wave regime has consisted of predictions of waves based on historical information for a period of no less than 10 years (Martínez and Coria, 1993; Naveau et al., 2005). Using this information, the most unfavorable extreme values of each year are selected, and the results are then extrapolated to different return periods.

Although there is no physical, theoretical, or empirical evidence of what the selection or adjustment of a probability distribution function should be for the calculation of the design wave height, the Gumbel or Fisher Tippett I and Weibull distribution functions are widely used for such purposes, as reported by Martínez and Coria (1993), Katz et al. (2002), García et al. (2004), and Naveau et al. (2005).

In response to the lack of information on the variability of extreme waves along the coast of the Colombian Caribbean, the main objective of this study is to determine the importance and contribution of cold fronts and tropical storms to extreme waves in order to ascertain the actions to which coastal and port structures in different regions of the Colombian Caribbean should be subjected and furthermore to assess the degree of threat to which coastal populations are exposed due to flood processes caused by wave run-up.

\section{Description of the study area}

The coastline of the Colombian Caribbean has a wide territory which extends from 8 to $13^{\circ} \mathrm{N}$ and from the country's border with Panamá in the southwest (SW) at longitude $79^{\circ} \mathrm{W}$ to the Guajira Peninsula in the northeast (NE) at longitude $71^{\circ} \mathrm{W}$. The Colombian coastal area is approximately $1600 \mathrm{~km}$ in length and includes important cities from both an economic and touristic perspective: Riohacha, Santa Marta, Barranquilla, and Cartagena.

The insular Colombian Caribbean is formed by the Archipelago of San Andrés, Providencia, Santa Catalina, the Roncador, Quitasueño, Serranía, and other cays, adjacent islets, and deep-water coral reefs.

San Andrés Island is located in the Caribbean Sea, $180 \mathrm{~km}$ to the east of Nicaragua and northeast of Costa Rica. The island is $480 \mathrm{~km}$ northwest of the Colombian coast (Parsons, 1954). The island of San Andrés is the largest of the islands that form part of the Archipelago of San Andrés, Providencia, and Santa Catalina, with a total extension of $26 \mathrm{~km}^{2}$. It is surrounded on its northwestern side by a small coral reef and several cays that are home to marine flora and fauna (Geister, 1973).

It is interesting to review and analyze the phenomenon responsible for the extreme wave regime in this area due to the fact that the area of the Colombian Caribbean in its entirety is not located at the same latitude.

The Colombian climate is characterized by two seasons in the year that are marked according to precipitation: a dry season and a wet season. The main dry season in the region occurs from December to May. In this season, swells produced by cold fronts may occur. The wet season occurs in the rest of the year, interrupted by a relative minimum in June and July known as an Indian summer (Andrade and Barton, 2001). The dry season and the Indian summer are associated with the jet stream winds of San Andrés and the northeastern (NE) trade winds. When the jet stream of San Andrés is stronger, the dry season occurs on the entire Caribbean coast, coinciding with very intense NE trade winds. The same occurs with the Indian summer (Andrade and Barton, 2001). By contrast, the wet season, which ranges from August to November, coincides with the time of the most intense jet stream winds from Chocó and the less intense jet stream winds from San Andrés (Poveda, 2004).

The annual wave cycle presents a bimodal form of behavior influenced by the NE trade winds, consisting of two wind periods, intense waves, and low precipitation in the dry season, and two wind periods, weak waves, and high precipitation during the wet season (Mesa, 2010).

\section{Methodology}

In the area under study, there are no extensive historical records of waves of an experimental nature (Meza, 2010). 


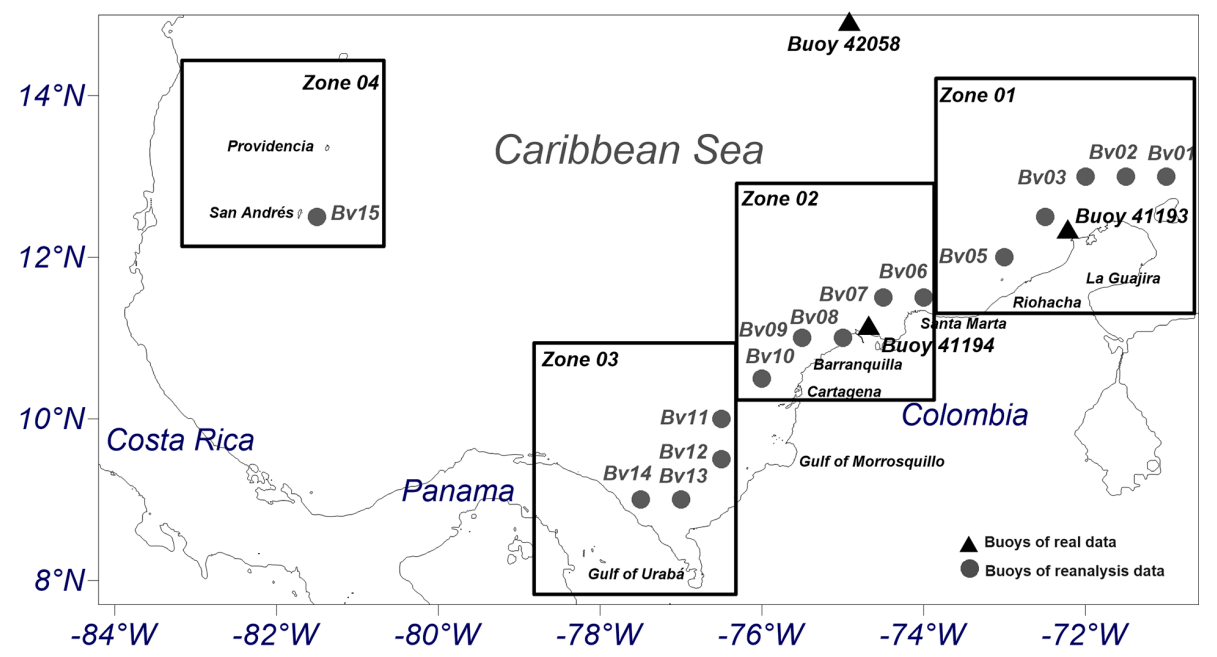

Figure 1. Location of the DIMAR and NOAA buoys on the Colombian Caribbean coast, and location of the 15 virtual buoys generated using WW3, including the zoning proposed by Ortiz (2012) based on the threat degree of hurricanes.

Buoys of the National Oceanic and Atmospheric Administration (NOAA) are extremely far from the coastal zone of the Colombian Caribbean. The DIMAR controls several directional buoys near the Colombian coasts in the Caribbean and the Pacific. For the Caribbean, the DIMAR has two buoys, 41193 and 41194, which are located near the coasts of Barranquilla and Riohacha, respectively. In the central Caribbean, the NOAA controls scalar buoy 42058, as shown in Fig. 1.

The National Data Buoy Center (NDBC) database has records for 2008, 2009, and 2010. Directional buoy 41194, which began operation in 2007, is located near Bocas de Ceniza, which is the mouth of the Magdalena River in the Caribbean Sea. It is located near the city of Barranquilla. Directional buoy 41193 is near Puerto Bolívar (Guajira Department) and has records since 2010, while buoy 42058 has been collecting data since 2005 . Therefore, in order to characterize the wave climate, it is necessary to implement data obtained from models, satellites, or visual waves (Agudelo et al., 2005). According to Martínez and Coria (1993), for an analysis of extreme waves it is necessary to have at least 10 years of wave data in the area of interest. For this purpose, a historic database of 30 years (1979-2009) from the reanalysis of 15 virtual buoys distributed along the Caribbean coastline from the NCEP Climate Forecast System Reanalysis (CFSR) winds, was initially analyzed (Chawla et al., 2011). These data were obtained online (http://polar.ncep. noaa.gov/waves/CFSR_hindcast.shtml). The spatial resolution of wave data for the Caribbean Sea is $1 / 6^{\circ} \times 1 / 6^{\circ}$. The wave model used at NCEP is a third-generation wind wave model, WAVEWATCH III ${ }^{\circledR}$ (Tolman, 2009). The wind fields with which the model was forced originate from a new reanalysis of the atmospheric, oceanic, sea ice, and land data between 1979 and 2010, as well as a reforecast run with this reanalysis (Saha et al., 2010). A detailed description of the data is carried out in Chawla et al. (2013).

The locations of these virtual buoys (BV) are shown in Fig. 1. This image also demonstrates the segmentation of the continental and insular Colombian Caribbean coast into 4 zones, as proposed by Ortiz (2012), in accordance with their level of vulnerability to the threat of hurricanes.

Given the limited information of oceanographic buoys in the area of study, detailed parametric calibration and validation were applied to the reanalyzed wave series for data coinciding with the significant wave heights $\left(H_{\mathrm{S}}\right)$ in undefined depths for the zone in the Caribbean where data from oceanographic buoys existed. In this study, the data from buoy 42058 were used for the calibration of the database, and the data from buoy 41194 were used for validation. Buoy 42058 was selected to perform the calibration process for two main reasons: the higher extension of continuous data available and its location in undefined depths.

From the data on significant wave heights $\left(H_{\mathrm{s}}\right)$ from the WW3 model for the point $14.9^{\circ} \mathrm{N}, 75^{\circ} \mathrm{W}$ and the data collected by oceanographic buoy 42058 , a detailed parametric calibration method was applied for coinciding data using power and linear regression models (Tomas, 2009). With the coefficients obtained in each regression model, the data from the series corresponding to buoy BV05 were corrected. These data were validated using the values of significant wave heights $\left(H_{\mathrm{s}}\right)$, as measured by oceanographic buoy 41194 of Barranquilla, Colombia.

With the aim of verifying the degree of adjustment of the measured and calculated time series, the $D$ adjustment index and the average deviation $P$, described by Willmott (1981), were applied. In order to determine the adjustment degree of the regression models, the $r^{2}$ correlation coefficient was used. 
In accordance with Wornon and Welsh (2002a, b), the $D$ index is very sensitive to errors in the mean square root of the difference between predictive and observed values. $D=0$ shows total dissociation, while $D=1$ shows a perfect association between the measured and calculated data. Willmott's $D$ index is defined as

$$
D=1-\frac{\sum_{n=1}^{N}(\mathrm{Pn}-\mathrm{On})^{2}}{\sum_{n=1}^{N}(|\mathrm{Pn}-O|+|\mathrm{On}-O|)^{2}} .
$$

Here, $\mathrm{Pn}$ is the prediction performed, On represents the measurements, and $O$ is the mean of the measurements performed.

The average deviation $P$ is defined as

$\operatorname{bias}(P)=\frac{\sum_{n=1}^{N}(\mathrm{Pn}-\mathrm{On})^{2}}{\sum_{n=1}^{N} \mathrm{On}}$.

For example, a deviation of -0.05 demonstrates mean underestimations of the order of $5 \%$.

To differentiate the influence of cold fronts on hurricanes, calculations of extreme values were performed in two seasons of the year: the hurricane season of the Caribbean from June to November, and the cold front season from December to May.

For the calculation of extreme values, Gumbel's maximum distribution or Fisher-Tippet's type I distribution were selected. This distribution is suitable for random, identically distributed, and independent variables and is widely used to characterize extreme regimes of oceanographic geophysical variables. Gumbel's maximum distribution is a bi-parametric function with a location parameter $\lambda$ and a scale parameter $\delta$ (García et al., 2004):

$F(x)=e^{-e^{-b}}$,

where

$b=\frac{x-u}{\alpha}$

$\alpha=\frac{S_{x}}{\lambda}$

$u=\bar{x}-\delta \alpha$.

Here, $x$ is the data series, $S_{x}$ is the standard deviation, and $\bar{x}$ the arithmetic mean of the data series. The values of $\lambda$ and $\delta$ are selected according to the number of data. In this case, $\lambda=0.53622$ and $\delta=1.11237$.

From the series of annual maximums, the characteristic waves for return periods of $5,10,25,50$, and 100 years were calculated using Gumbel's maximum distribution.

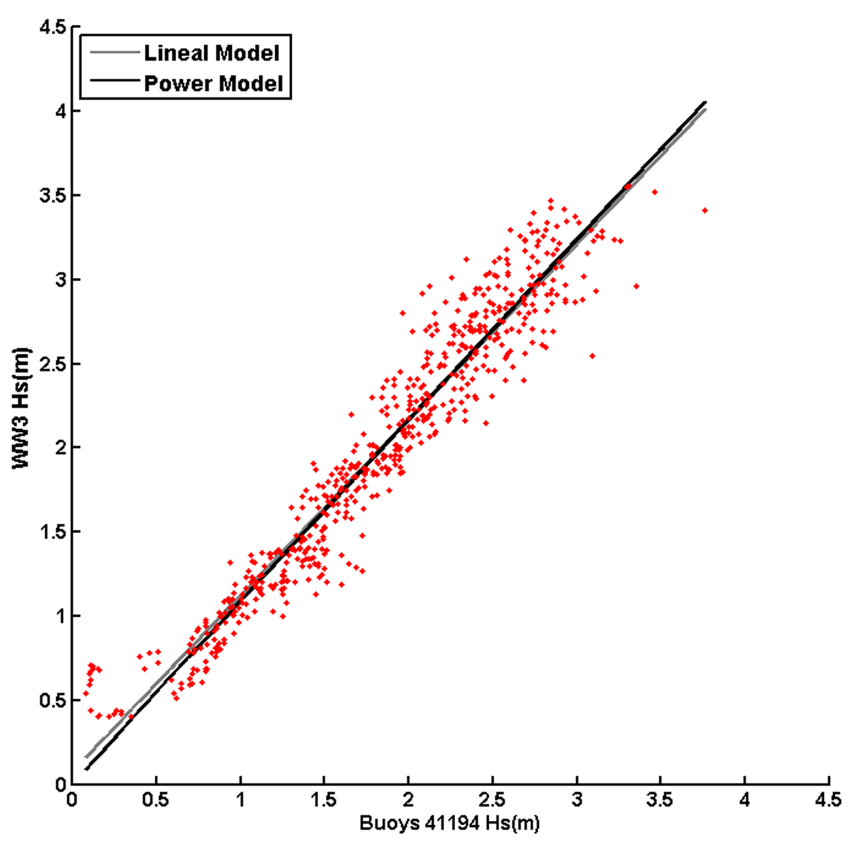

Figure 2. Scalar calibration using power and linear regression models of $H_{\mathrm{S}}$ WW3 with coinciding data from the central Caribbean buoy $(n=594)$.

\section{Analysis and results}

The results of the calibration of the $H_{\mathrm{S}} \mathrm{WW} 3$ reanalysis data and the data from the central Caribbean oceanographic buoy (42058) can be seen in Fig. 2. The lines represent the linear regression Eq. (7) and power regression Eq. (8) models. The dispersion diagram shows that both models present a good correlation with the data, with $r^{2}$ values of 0.92 and 0.93 for the power and linear regression models, respectively. The calibration equations obtained were the following:

$H_{\text {scal }}=\alpha H_{\text {sbuoys }}+\beta(\alpha=1.047 \pm 0.024$;

$\beta=0.07619 \pm 0.047)$

$H_{\text {scal }}=a H_{\text {sbuoys }}^{b}(a=1.096 \pm 0.0265$;

$b=0.9847 \pm 0.0284)$.

Based on the previous calibration relations, the $H_{\mathrm{S}}$ data from the WW3 model in the coordinate point $11.25^{\circ} \mathrm{N}-74.75^{\circ} \mathrm{W}$ (coinciding with the location of buoy 41194) were corrected.

The uncorrected $H_{\mathrm{s}}$ values of the WW3 model and the data from buoy 41194 are compared in Fig. 3a, with $D=0.97$ and a bias $(P)=-0.06$. Figure $3 \mathrm{~b}$ and c compare the $H_{\mathrm{s}}$ series from buoy 41194 with the $H_{\mathrm{s}}$ series corrected using a linear and power regression model, respectively. Based on the adjustment index $D$ and Willmott's average deviation $P$, the improvement in the adjustment degree in the $H_{\mathrm{s}}$ time series is shown in Table 1. As demonstrated in the table, the indices show improvements of equal proportion for both models. In this sense, the linear regression model was selected for the 

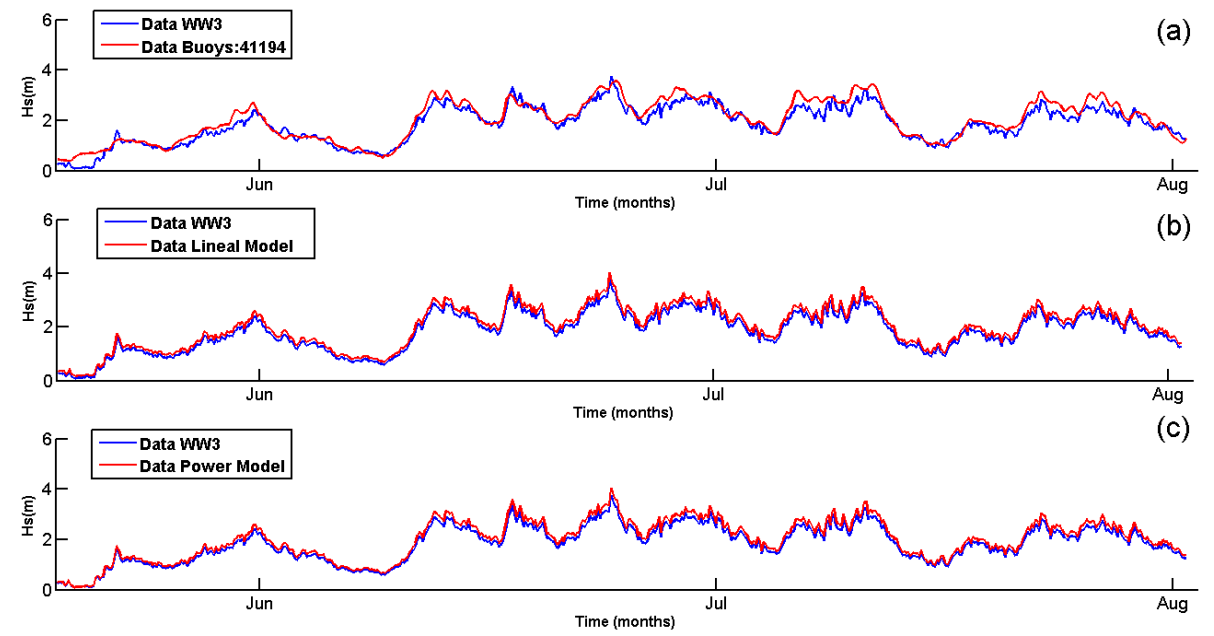

Figure 3. Validation of the $H_{\mathrm{S}}$ time series $(m)$ corresponding to the year $2009(n=767)$. (a) Buoy 41194 and WW3 data without calibration. (b) Buoy 41194 and data corrected with the linear model. (c) Buoy 41194 and data corrected with the power model.

correction of the WW3 $H_{\mathrm{s}}$ series from the 15 points selected for the analysis.

Once the information of the data for each of the 15 buoys was calibrated and validated, we proceeded to perform a detailed analysis from which a total of eight buoys were selected as representative samples of each of the zones of interest based on the $H_{\mathrm{s}}$ value and the location of the cities and ports of interest.

As noted above, tropical cyclones occur in the season from June to November, and cold fronts occur from December to May. Therefore, the $H_{\mathrm{s}}$ time series of the eight buoys were divided for these two seasons with the objective of achieving independently performed extreme wave analysis. That is, the extreme regime was calculated considering only the $H_{\mathrm{S}}$ information for the months between June and November, and another extreme regime was calculated, only taking into account the months from December to May. Additionally, the extreme regime was calculated considering the complete series in an effort to identify which seasons of the year contributed the most to this regime. This method of presenting the results allows a comparative analysis to identify in which seasons of the year the most extreme waves for the area occur and also to establish which atmospheric phenomenon is responsible for generating these extreme waves.

The results of the application of Gumbel's theory for the significant height $H_{\mathrm{s}}$ on each of the eight buoys are shown in Figs. 4, 7, 8, and 9 in the same order in which the previous results were presented.

Virtual buoys BV01-BV05 are located in the arid zone of the Alta Guajira, in the northeast of the Colombian Caribbean (zone 1 in Fig. 1). The bar diagrams in Fig. 4 explicitly show that the height of extreme waves is clearly influenced by tropical cyclones. During this period, the extreme waves associated with return periods of 5 and 10 years oscillate between 3.2 and $4.5 \mathrm{~m}$. For return periods of 25, 50, and 100 years,
Table 1. Adjustment index $D$ and Willmott's average deviation $P$, data from buoy 41194 and WW3 model.

\begin{tabular}{lll}
\hline Significant height $H_{\mathrm{S}}(m)$ & $D$ & Bias $(P)$ \\
\hline WW3 vs. buoy (41194) & 0.97 & -0.06 \\
WW3 corrected with linear & 0.99 & 0.02 \\
Regression vs. buoy (41194) & & \\
WW3 corrected with power & 0.99 & 0.02 \\
Regression vs. buoy (41194) & & \\
\hline
\end{tabular}

there is a probability of exceedance of 4,2 , and $1 \%$ respectively, varying between 5.5 and $6.6 \mathrm{~m}$ in height. The higher waves for this region occur because Alta Guajira is the closest zone to the trajectory of tropical cyclones passing through the Colombian Caribbean (Ortiz, 2012).

Conversely, the dry season of the year (from December to May) is influenced by the increase of trade winds from the northeast (Bernal et al., 2006; Paramo et al., 2011) and the passage of cold fronts coming from the Northern Hemisphere, an event which produces strong tides (Ortiz et al., 2013). Extreme wave heights covering return periods of 5 and 10 years show significant heights which oscillate between 3 and $4.2 \mathrm{~m}$. Meanwhile, the extreme waves for return periods of 25, 50, and 100 years take significant height values which vary between 3.6 and $4.8 \mathrm{~m}$.

Regarding the direction of the waves, it is considered that this is likely from $\mathrm{E}$ and ENE with heights generally between 1 and $3 \mathrm{~m}$.

When comparing the extreme regime for virtual buoys BV01 and BV03 located in the Alta Guajira area, it can be observed that the significant heights (for return periods of 5 and 10 years which take the complete series of annual maximums) show values greater than the significant heights ob- 

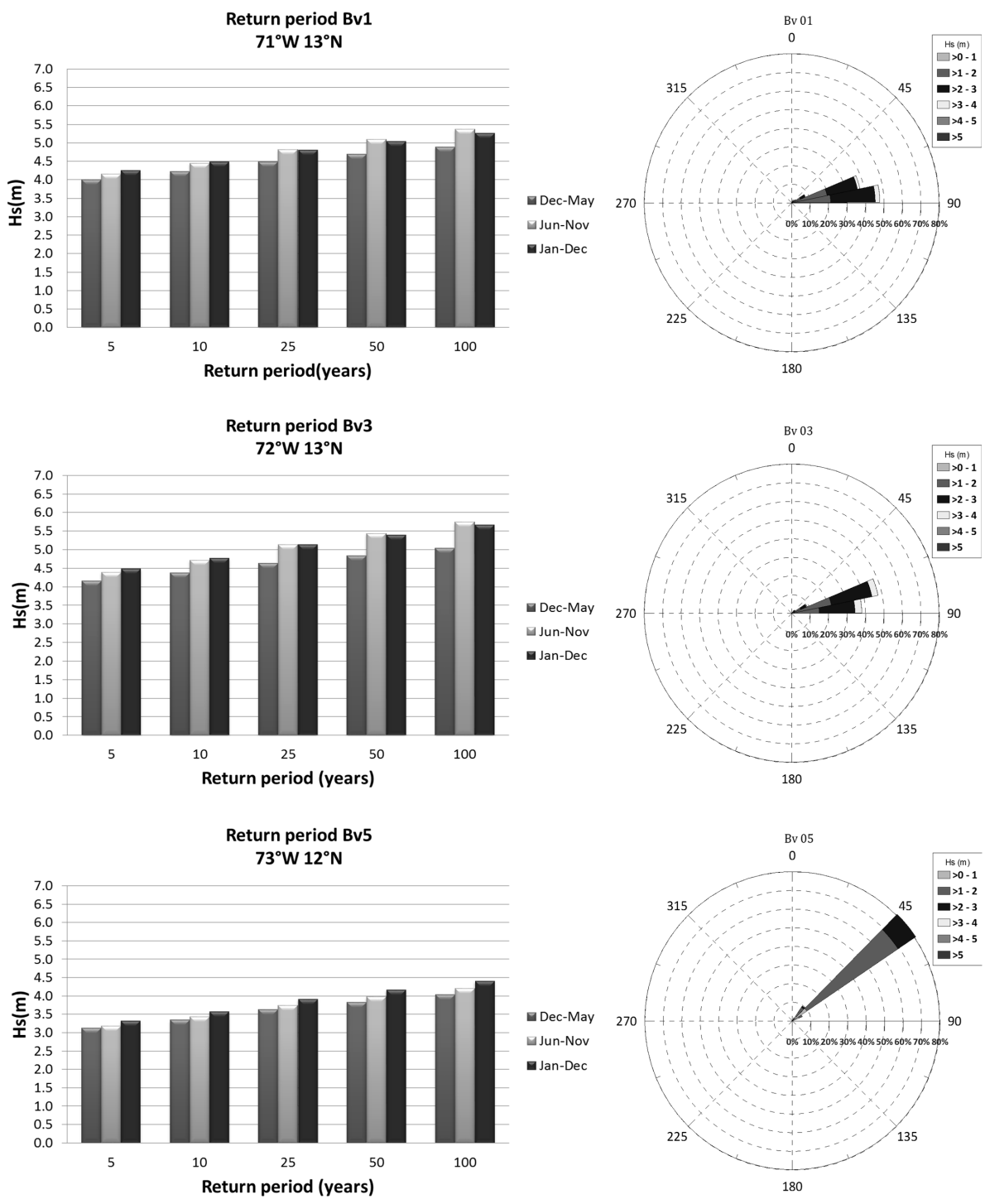

Figure 4. Return periods for $H_{\mathrm{s}}$ of virtual buoys BV01-BV05 (zone 1).

tained when dividing the series by season. However, for a return period of more than 50 years, the significant height extrapolated from the cyclone season data surpasses the significant height obtained within the annual maximums. This occurs because, over the 30 years of the registry, there were 16 years in which the maximum significant height occurred in hurricane season. These values were the highest of the record (between 4.9 and $5.2 \mathrm{~m}$ ). In the remaining 14 years, the maximum significant height in cyclone season is lower in comparison to the wave height registered in the cold front season. This variation in the significant height for each period generates a greater dispersion in the maximum point of the season from June to November. The difference in the standard deviation of data causes an increase in the slope of the line $H_{\mathrm{s}}$ against the return period in the semi-logarithmic space (Fig. 5) of the model for the cyclone season. In the re- maining virtual buoys, there is no variation in the extreme regime when increasing the return period because all the extreme wave events are found to be related to one of the two seasons as shown in Fig. 6.

The diagrams of Fig. 7 correspond to the central zone of the Colombian Caribbean formed by Baja Guajira, Santa Marta, Barranquilla, and Cartagena (zone 2 in Fig. 1). It can be seen that in BV06, for both the cyclone season (June-November) and the cold front season (DecemberMay), there are similar magnitudes in the extreme waves. However they present slightly higher values in the dry season, especially in the return periods of 5 and 25 years. From BV09, it can be observed that the most energetic waves in the coastal zone of this region are clearly influenced by cold fronts, whereas the less energetic waves are dominated by tropical cyclones. Therefore, the extreme waves for return 


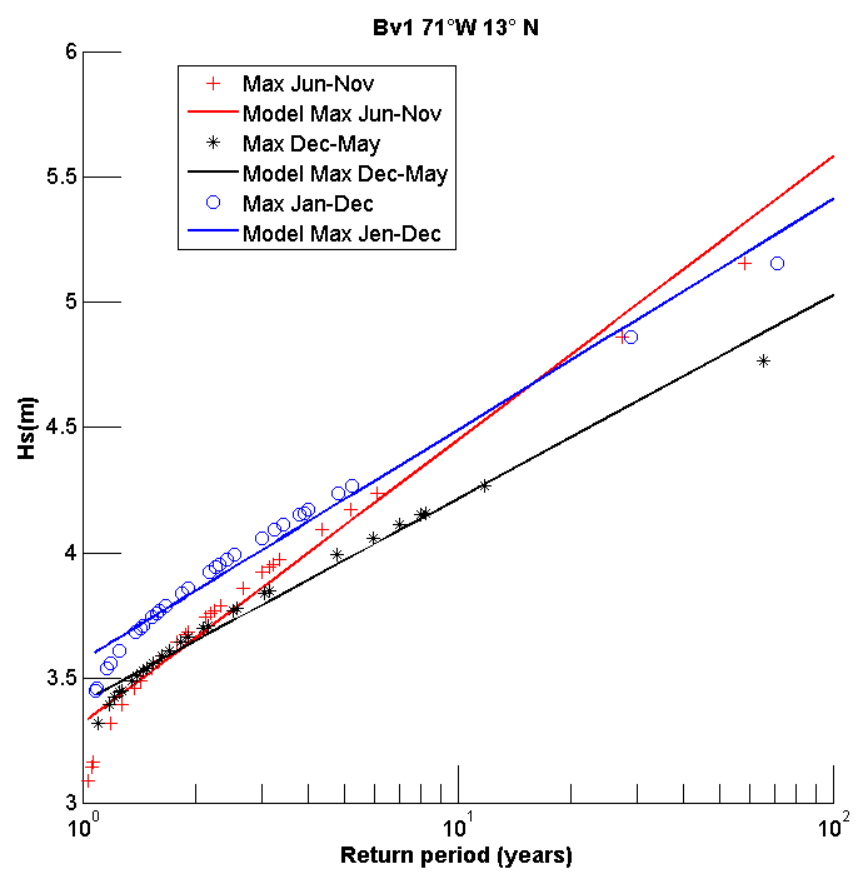

Figure 5. Comparison of the extreme wave regime in virtual buoy 01 , considering the maximums of the complete series, the maximums of the cold front season, and the maximums of the hurricane season.

periods of 5 and 10 years register significant heights between 3.5 and $4.5 \mathrm{~m}$, and the extreme waves for return periods of 25,50 , and 100 years present values that vary between 4 and $5.5 \mathrm{~m}$ in height.

In this transition region, the behavior of extreme waves is modified because a clearer and stronger preponderance of cold fronts begins, decreasing the influence of tropical storms on this regime. This modification can clearly be seen in Fig. 7, where the extreme regime calculated considering the complete series is influenced by the maximum wave heights which occur in the cold front season.

It is important to highlight that the extreme wave height regime in one area of the central zone of the Caribbean is higher than in Alta Guajira (i.e., buoy 09). This zone of the Colombian coast ceases to be directly influenced by tropical cyclones and the extreme regime prevails due to the passage of cold fronts.

In relation to the direction of the waves, it is reported that in this sector of the central Colombia Caribbean, the NE direction is predominant with heights mainly between 1 and $3 \mathrm{~m}$. With respect to zone 1 , the energy in the average regime is similar, and the direction of the wave trains is affected by the orientation of the coastline, which stretches from NE to SW.

The data shown in Fig. 8 correspond to the zone known as the western Caribbean, which consists of the area between the Morrosquillo Gulf and the Urabá Gulf (zone 3 in Fig. 1).

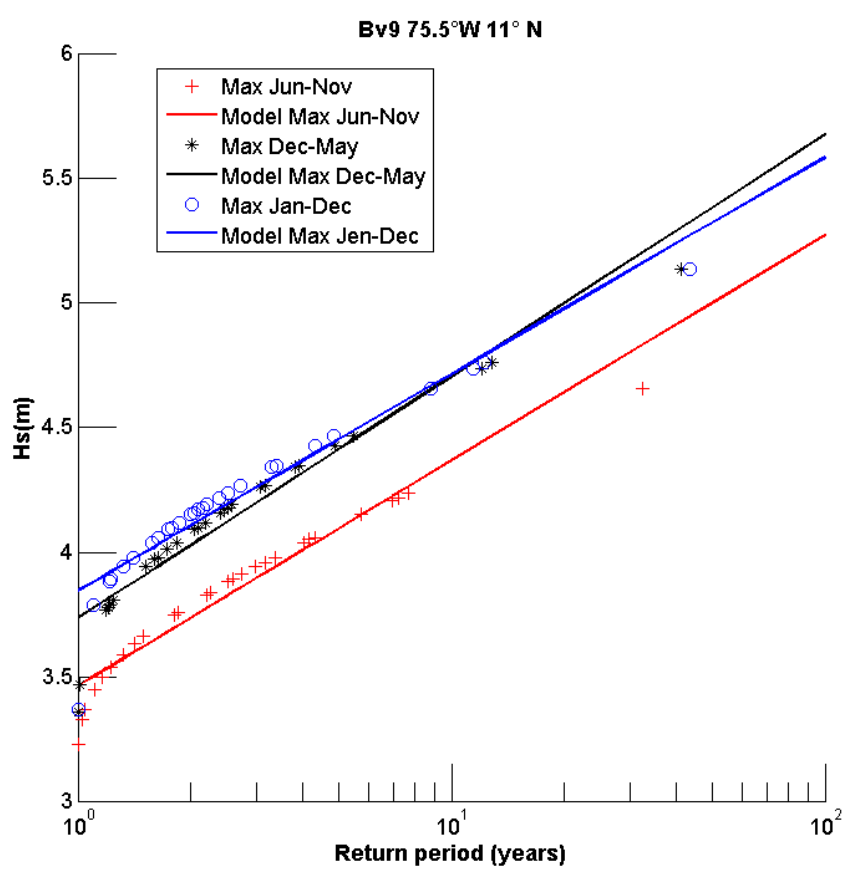

Figure 6. Comparison of the extreme wave regime in virtual buoy 09 , considering the maximums of the complete series, the maximums of the cold front season, and the maximums of the hurricane season.

In this zone, regardless of the season, the wave energy is lower in comparison to the other zones of the Colombian Caribbean. This is because the Morrosquillo Gulf is shielded from winds by Boquerón Island and the other islands of San Bernardo. For its part, the Urabá Gulf is protected from waves in the eastern zone, and Colombia bay is protected by its closed "U" shape.

The bar diagrams in Fig. 8 show that the least energetic waves of the entire Colombian coast, which are mainly influenced by the passage of cold fronts, can be found in this area. The significant height for return periods of 5 and 10 years show values oscillating between 4 and $4.5 \mathrm{~m}$, and the extreme waves for return periods of 25,50 , and 100 years assume values which vary between 4.5 and $5 \mathrm{~m}$ in height. On the other hand, the least energetic extreme waves are dominated by tropical cyclones. In these graphics, it is evident that the extreme wave height is clearly influenced by cold fronts, a fact which is confirmed when the values of the extreme wave heights are calculated taking into account the complete series of maximum heights. Regarding the direction of waves in the southwestern sector of the Colombian Caribbean, NE and NNE are predominant, with heights generally ranging between 1 and $2 \mathrm{~m}$. Regarding zones 01 and 02 , the energy in the average regime is lower.

BV15 is located in the insular region of San Andrés and Providencia (zone 4 in Fig. 1). In Fig. 9, it can be seen that extreme waves for return periods of 5 and 10 years have sig- 

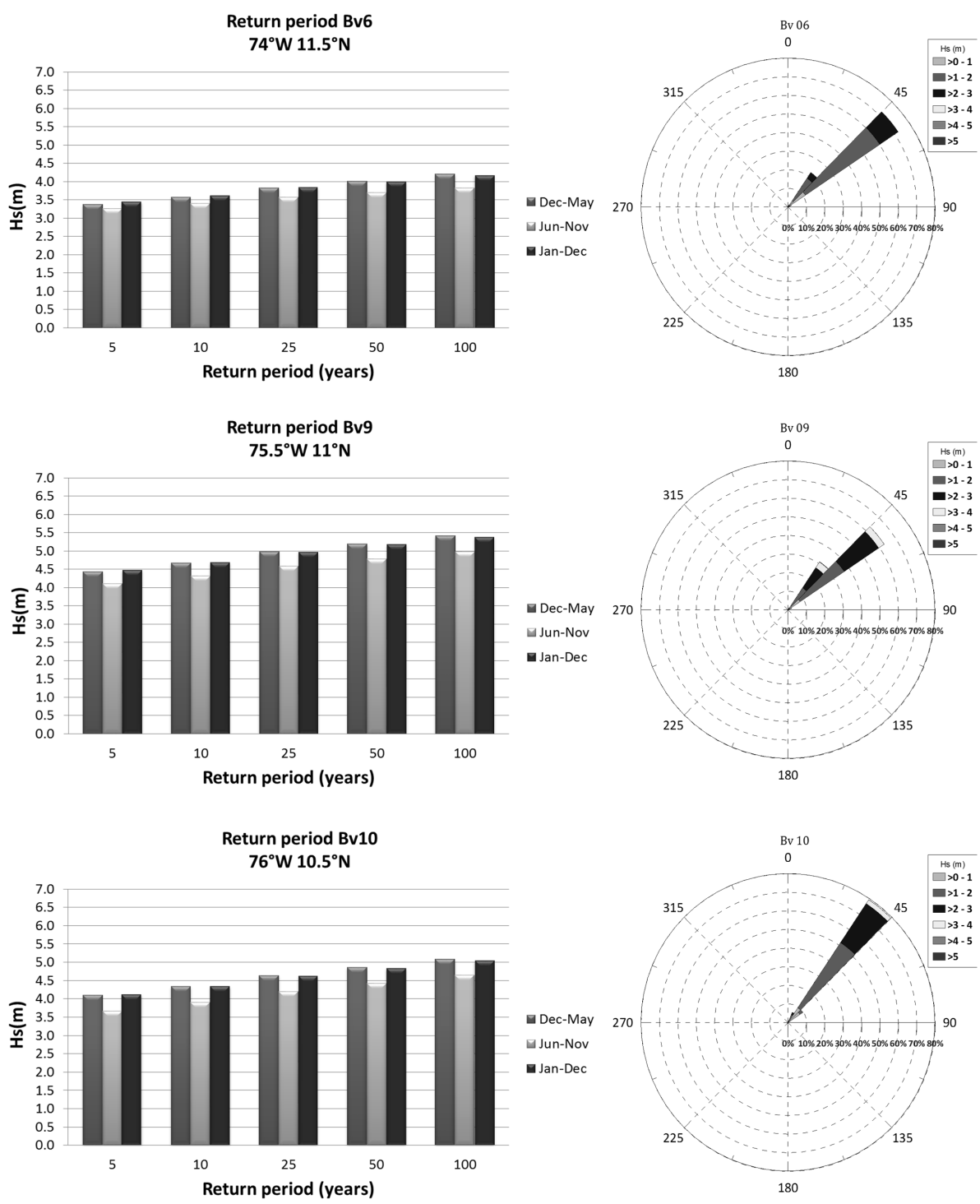

Figure 7. Return periods for $H_{\mathrm{S}}$ of virtual buoys BV06-BV10 (zone 2).

nificant height values between 5 and $5.5 \mathrm{~m}$ for the wet season (on account of hurricanes and tropical storms), while for the dry season (with the influence of cold fronts), the values oscillate between 4.5 and $4.7 \mathrm{~m}$. The extreme waves for return periods of 25,50 , and 100 years assume values which vary between 5.1 and $5.7 \mathrm{~m}$ in height for the dry season (as influenced by cold fronts), while for the wet season, the values for extreme waves oscillate between 6.2 and $7 \mathrm{~m}$. Due to their geographic location in the Caribbean Sea, the islands of San Andrés and Providencia exhibit high vulnerability to tropical storms and the passage of cold fronts (Ortiz et al., 2014b). Regardless of the analyzed series, it is clearly evident that the waves generated by tropical storms are the waves which govern the extreme regime. This is due to the location of San Andrés and Providencia islands in an area of high hurricane frequency.
Previous studies have revealed that, according to historical records for the years 1900 to 2013, a total of 17 hurricanes have affected San Andrés and Providencia. Furthermore, in seven of these phenomena, the eye of the storm was located less than $150 \mathrm{~km}$ from the islands. Of these seven hurricanes, Hurricane Joan in 1988 generated the highest wave heights, with significant height values of $5 \mathrm{~m} \mathrm{SE}$ of the island of San Andrés in the $50 \mathrm{~m}$ isobaths (Ortiz et al., 2015). It is important to highlight that, over the last 50 years, of all the hurricanes which have affected the island of San Andrés, only Hurricane Joan has generated wave heights of $7.8 \mathrm{~m}$ (Ortiz et al., 2015). Nevertheless, values higher than $5 \mathrm{~m}$ have been registered during that season due to the passage of hurricanes. In the analysis of 30 years of the dry season for BV15, heights superior to $5 \mathrm{~m}$ were not encountered. This finding suggests that wave heights in the extreme regime associated 

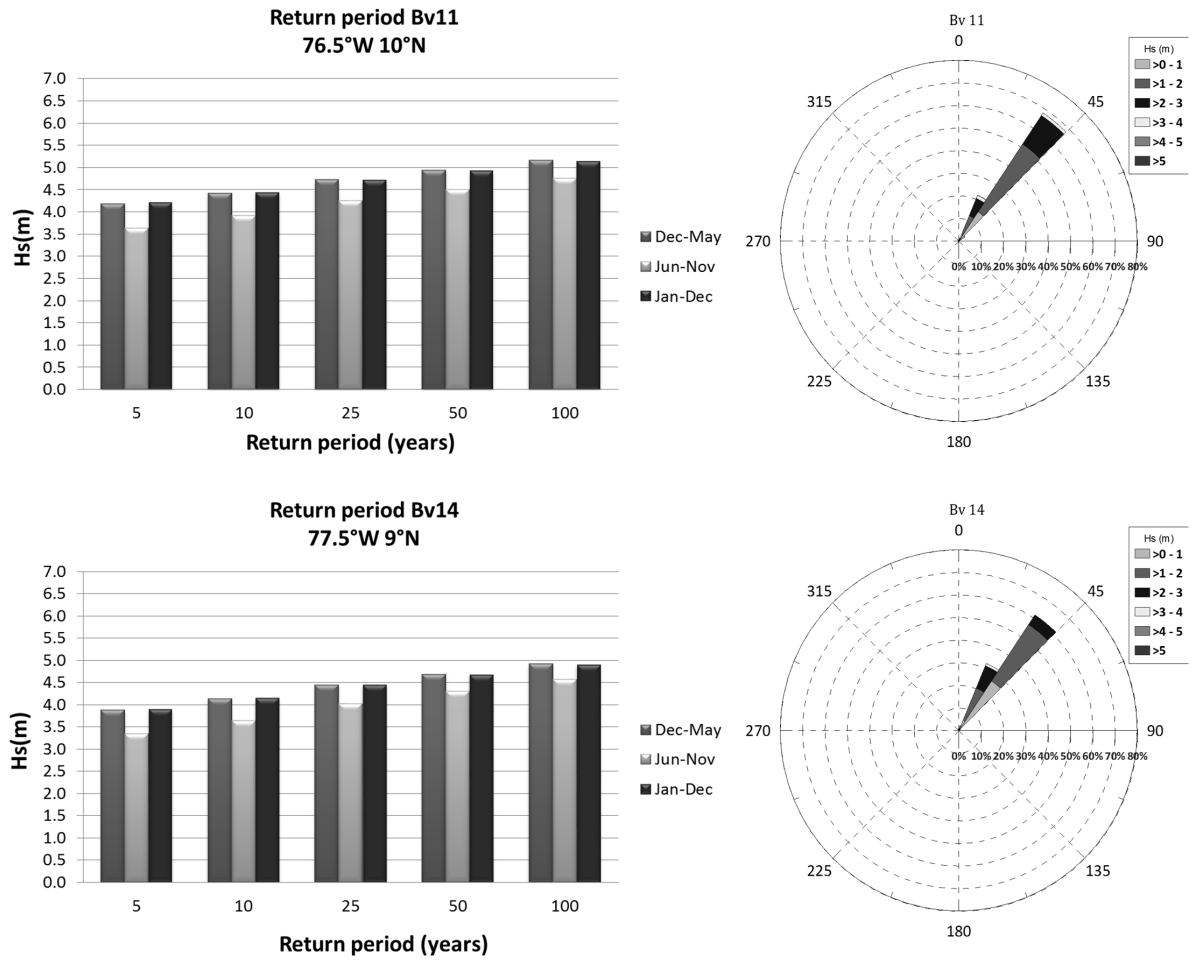

Figure 8. Return period for $H_{\mathrm{S}}$ of virtual buoys BV11-BV14 (zone 3).
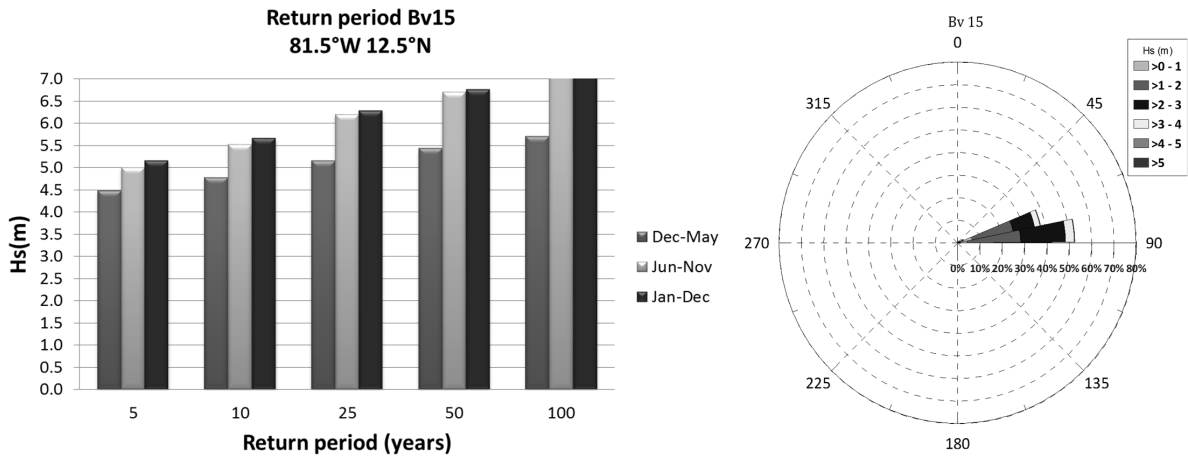

Figure 9. Return periods for $H_{\mathrm{S}}$ of virtual buoys BV15 (zone 4).

with the passage of tropical storms in zone 4 have lower return periods than the wave heights associated with the cold fronts season.

\section{Conclusions}

The present study has led to the conclusion that extreme waves along the Colombian Caribbean coasts (continental and insular) are not simply generated by the same forces. The geomorphology of the $1600 \mathrm{~km}$ of coastline of the Colombian Caribbean and its geographical position ensure that the waves generated by extreme events do not have the same magnitude of influence in all areas. There is a clear differ- ence between the north zone (Alta Guajira), central zone (Baja Guajira, Santa Marta, Barranquilla, and Cartagena), west zone (Morrosquillo Gulf and Urabá Gulf), and the Archipelago of San Andrés because the extreme regime of the waves is influenced by the spatial and temporal changes of the atmospheric phenomena which develop over a particular zone on the Colombian Caribbean coast, depending on the dry and wet climatic seasons.

Based on the analysis of the variability of extreme waves in the continental coast of the Colombian Caribbean, it can be concluded that in the higher part of the Guajira (zone 1), there are higher extreme wave heights caused by tropical cyclones. This fact is consistent with the findings reported in Ortiz (2012). This area is followed by the central zone (zone 
2), where the influence of extreme waves is associated with the passage of cold fronts. Less energetic extreme waves occur in the western part of the Caribbean (zone 3), where they are mainly forced by the passage of cold fronts.

The extreme waves in the insular region of San Andrés and Providencia (zone 4) show a dynamic different from the continental region due to its geographic location. Although the heights of the waves in the extreme regime are similar in magnitude to those found for zone 1 (Alta Guajira), the extreme waves associated with the passage of tropical storms in this zone have lower return periods than the extreme waves associated with the cold fronts season.

The aforementioned results make a valuable contribution towards determining the extreme regime and the design waves for the construction of coastal infrastructure. Furthermore, the results provide an important component for the planning of alert and mitigation strategies against marine meteorological threats. In addition, because different zones of the Colombian Caribbean are affected by coastal erosion, this study constitutes a source of data for the further analysis of how, and to what extent, these events are related to erosion.

Acknowledgements. The authors wish to express their gratitude to the Directorate of Research and Projects (Dirección de Investigaciones y Proyectos (DIDI)) of the Universidad del Norte and to the Departamento Administrativo de Ciencia y Tecnología e Innovación de Colombia (COLCIENCIAS) for their support in conducting this research.

Edited by: M. Gonzalez Rodríguez

Reviewed by: two anonymous referees

\section{References}

Agudelo, P., Restrepo, A., Molares. A., Tejada. C., Torres. R., and Osorio, A.: Determinación del clima medio y extremal en el Caribe Colombiano [Determination of the average and extreme climate in the Colombian Caribbean]. Boletín Científico CIOH, 23, 33-45, 2005.

Andrade, C. and Barton, E.: Eddy development and motion in the Caribbean Sea, J. Geophys. Res., 105, 26191-26201, 2001.

Bernal, G., Poveda, G., Roldán, P., and Andrade, C.: Patrones de variabilidad de las temperaturas superficiales del mar en la Costa Caribe Colombiana [Variability patterns of the sea surface temperatures in the Colombian Caribbean coast], Rev. Acad. Colomb. Cienc., 30, 195-208, 2006.

Chawla, A., Spindler, D., and Tolman, H. L.: A thirty year wave hindcast using the latest NCEP Climate Forecast System Reanalysis winds, Proc. 12th Int. Workshop on Wave Hindcasting and Forecasting, Waikoloa, HI, Environment Canada, I1, 2011.

Chawla, A., Spindler, D., and Tolman, H. L.: Validation of a thirty year wave hindcast using the Climate Forecast System Reanalysis winds, Ocean Modell., 70, 189-206, 2013.

García, V., Garcia-Bartual, R., Cabrera, E., Arregui, F., and García, J.: Stochastic Model to Evaluate Residential Water Demands, J. Water Plan. Manage., 130, 386-394, 2004.
Geister, J.: Los arrecifes de la isla de San Andres (Mar Caribe, Colombia) [The coral reefs in the island of San Andrés (Caribbean Sea, Colombia)], Mitt Inst. Colombo Alemán Invest. Cient., 7, 211-228, 1973.

Katz, R. W., Parlange, M. B., and Naveau, P.: Statistics of extremes in hydrology, Adv. Water Resour., 25, 1287-1304, 2002.

Martínez, A. and Coria, P.: Distribución de probabilidad de la altura del oleaje dentro de la bahía de Todos los Santos, B.C. [Probability distribution of waves' height inside the Todos los Santos Bay, B.C.], México, Ciencias Marinas, 19, 203-218, 1993.

Mesa, J. C.: Metodología para el reanálisis de series de oleaje para el caribe colombiano [Methodology for the re-analysis of wave series for the Colombian Caribbean]. Tesis Doctoral, Universidad Nacional de Colombia, Colombia, Medellin, 5-12, 2010.

Naveau, P., Nogaj, M., Ammann, C., Yiou, P., Cooley, D., and Jomelli, V.: Statistical methods for the analysis of climate extremes, C. R. Geosci., 337, 1013-1022, 2005.

Ortiz, J. C.: Exposure of the Colombian Caribbean Coast, including San Andrés Island, to Tropical Storms and Hurricanes, 19002010, Nat. Hazard J., 61, 815-827, 2012.

Ortiz-Royero, J. C., Otero, L. J., Restrepo, J. C., Ruiz, J., and Cadena, M.: Cold fronts in the Colombian Caribbean Sea and their relationship to extreme wave events, Nat. Hazards Earth Syst. Sci., 13, 2797-2804, doi:10.5194/nhess-13-2797-2013, 2013.

Ortiz, J. C., Salcedo B., and Otero, L.: Investigating the collapse of the Puerto Colombia Pier (Colombian Caribbean Coast) in March of 2009: methodology for the reconstruction of extreme events and their impact on the coastal infrastructure, J. Coast. Res., 30, 291-300, 2014.

Ortiz, J. C., Plazas, J. M., and Lizano, O.: Evaluation of Extreme Waves Associated with Cyclonic Activity on San Andrés Island in the Caribbean Sea since 1900, J. Coast. Res., J. Coast. Res., 31, 557-568, 2015.

Paramo, J., Correa, M., and Núñez, S.: Evidencias de desacople físico-biológico en el sistema de surgencia en La Guajira, Caribe colombiano [Evidence of the physico-biological decoupling of the upwelling system in La Guajira, Colombian Caribbean]. Revista de biología marina y oceanografía, 46, 421-430, 2011.

Parsons, J. J.: English Speaking Settlement of the Western Caribbean, Yearbook of the Association of Pacific Coast Geographers, 16, 3-16, 1954.

Poveda, G.: La hidroclimatología de Colombia: una síntesis desde la escala inter-decadal hasta la escala diurna [The hydroclimatology of Colombia: a synthesis from the inter-decade scale to the diurnal scale], Rev. Acad. Colomb. Cienc., 28, 201-222, 2004.

Saha, S., Moorthi, S., Pan, H. L., Wu, X., Wang, J., Nadiga, S., Tripp, P., Kistler, R., Woollen, J., Behringer, D., Liu, H., Stokes, D., Grumbine, R., Gayno, G., Wang, J., Hou, Y. T., Chuang, H. Y., Juang, H. M. H., Sela, J., Iredell, M., Treadon, R., Kleist, D., Van Delst, P., Keyser, D., Derber, J., Ek, M., Meng, J., Wei, H., Yang, R., Lord, S., Van Den Dool, H., Kumar, A., Wang, W., Long, C., Chelliah, M., Xue, Y., Huang, B., Schemm, J.-K., Ebisuzaki, W., Lin, R., Xie, P., Chen, M., Zhou, S., Higgins, W., Zou, C. Z., Liu, Q., Chen, Y., Han, Y., Cucurull, L., Reynolds, R. W., Rutledge, G., and Goldberg, M.: The NCEP climate forecast system reanalysis, B. Am. Meteor. Soc., 91, 1015-1057, 2010.

Tolman, H. L.: User manual and system documentation of WAVEWATCH III version3.14, Tech. Note 276, NOAA/NWS/NCEP/MMAB, 220 pp., 2009. 
Tomas, A.: Metodologías de calibración de bases de datos de reanálisis de clima marítimo [Methodologies of the calibration of marine climate reanalysis database]. Tesis Doctoral, Universidad de Cantabria., Spain, 69-89, 2009 .

Willmott, C.: On the validation of models Phys. Geog., 2, 183-194, 1981.
Wornon, S. and Welsh, D.: An MPI quasi time-accurate approach for nearshore wave prediction using SWAN code - Part I, Coast. Eng. J., 44, 247-256, 2002a.

Wornon, S. and Welsh, D.: An MPI quasi time-accurate approach for nearshore wave prediction using SWAN code - Part II, Coast. Eng. J., 44, 257-280, 2002b. 